\title{
K-12 Education in the United States
}

Should We Implement National Standards and Assessments?

Jessica McKinney

In the face of increasing technical demands from the international labor market, U.S. students' math and science scores indicate a competitive disadvantage. Presently, states and equivalent state-level units ${ }^{1}$ control content standards and assessments for all students, creating over 50 distinct systems of measuring student success. This paper examines the possible use of national-level standards and assessments and evaluates such a policy based on effectiveness, political feasibility, cost, and administrative feasibility. Instituting national standards and assessments for elementary and secondary students could improve the competitiveness of the workforce in the United States if the standards are set at rigorous levels.

\section{Introduction}

State and local governments currently bear primary responsibility for education in the United States. Lacking a constitutional mandate, the federal government plays an ambiguous role in primary and secondary education. Because the Constitution does not explicitly mention education, education policy falls under the Tenth Amendment's instruction that "powers not delegated to the United States by the Constitution, nor prohibited to it by the States, are reserved to the States respectively, or to the people" (U.S. Const. amend X). By contrast, many other countries, including some of the United States' closest allies and strongest economic challengers, assert a more centralized role in education. In so doing, these countries estab- 
lish a consistent level of quality for their labor force. The United States needs strong intellectual performers to maintain its economic standing in a rapidly changing world. This paper examines the possibility of adopting a single set of national education performance standards upon which uniform national student achievement assessments can be based. This paper also compares a national education policy alternative to the current system of state-level standards and tests.

Policymakers constantly seek to better understand the critical elements of programs. To the extent possible, they link quantifiable inputs with results. There are many inputs that affect student performance and workplace readiness, including school funding, class size, socioeconomic circumstances, and parent education. This paper will focus on two critical inputs for public elementary and secondary schools in the United States: content standards and student assessment. Content standards evaluate knowledge and skill based on grade level and subject. Student assessment generally occurs in the form of standardized tests. The academic literature in the field of education policy is mixed with respect to the impacts of standards and assessment on student achievement.

This paper will analyze national standards and assessments based on effectiveness, political feasibility, cost, and administrative feasibilitycommonly used criteria that assess both implementation issues and direct results (Patton and Sawicki 1993). These criteria will show whether a policy succeeds at its stated goal (effectiveness), is a functional possibility (cost and administrative feasibility), and is likely to be accepted by major stakeholders (political feasibility). By balancing these four criteria, this paper demonstrates the trade-offs between the status quo and national-level standards and assessments.

\section{Problem Definition}

The federal No Child Left Behind Act of 2001 (NCLB) requires annual standardized testing for the third through eighth grades and some high school courses. Under NCLB, states must establish standards on which to base the assessments. The law asserts that states should identify the 
number of students scoring in "below basic," "basic," "proficient," and "advanced" categories, and it requires states, districts, and schools to ensure that the percentage of students who meet those standards (by achieving "proficient" or "advanced" level scores) increases annually. NCLB contains a variety of consequences if the number of students meeting the standards does not increase. ${ }^{2}$ However, it leaves the development and content of the tests to the state (NCLB 2001). This creates distinct educational expectations in each state. Although states are showing student improvements on the state-created standardized tests, results on a non-binding national test, the National Assessment of Educational Progress (NAEP), do not always reflect the same trend (Kober, Chudowsky, and Chudowsky 2008). This disparity draws the adequacy of state tests into question.

The variation in state tests is evidence of the inconsistency in curricula throughout the United States. Though the literature is mixed, effective use of content standards can correlate with higher student achievement on standardized tests (McCaffrey et al. 2001; Schoen et al. 2003). It seems logical to conclude that widely dissimilar preparation of students results in a future workforce with disparate skill sets. Because the U.S. economy relies on the supply of skilled laborers, this country's ability to compete internationally depends on strong technical preparation for workers nationwide.

International testing shows that students in the United States score lower than those in other countries. Since 2000, the Organization for Economic Cooperation and Development (OECD), a group of nations with developed economies, has administered triennial international assessments (Program for International Student Assessment, or PISA, exams) in reading, mathematics, and science. ${ }^{3}$ Fifteen-year-old students in the United States scored below 14 other nations in math and 23 other nations (out of 41) in reading on the 2003 exam (Lemke et al. 2004, 72, 104). ${ }^{4}$ Students in the United States scored significantly below the OECD average in both math and science in 2006, placing 29th in math and 35th in science out of 57 OECD members and partner nations (OECD 2007).

Further examination of the distribution of scores raises questions about the competitiveness of students in the United States. Students performed below the OECD average (measured as a score of 500 on the PISA exam) 
Table 1:

U.S. PISA Scores Compared to OECD Scores

\begin{tabular}{|l|c|c|c|c|}
\hline \multicolumn{1}{|c|}{ Test } & \multicolumn{2}{|c|}{$\begin{array}{c}\text { 2003 Average Scores (and } \\
\text { Proficiency Level) }\end{array}$} & \multicolumn{2}{c|}{$\begin{array}{c}\text { 2006 Average Scores (and } \\
\text { Proficiency Level) }\end{array}$} \\
\hline & OECD & U.S. & OECD & U.S. \\
\hline Math & $\begin{array}{c}500 \\
\text { (Mid 3) }\end{array}$ & $\begin{array}{c}483^{*} \\
(\text { Low 3) }\end{array}$ & $\begin{array}{c}498 \\
(\text { Mid 3) }\end{array}$ & $\begin{array}{c}474^{*} \\
(2)\end{array}$ \\
\hline Science & $\begin{array}{c}500 \\
(-1)\end{array}$ & $\begin{array}{l}491^{*} \\
\left(-^{1}\right)\end{array}$ & $\begin{array}{c}500 \\
(\mathrm{Mid} 3)\end{array}$ & $\begin{array}{c}489^{*} \\
(\text { Low 3) }\end{array}$ \\
\hline Reading & 494 & 495 & 492 & $-^{2}$ \\
& $(3)$ & $(3)$ & $\left(-^{2}\right)$ & $\left(-^{2}\right)$ \\
\hline
\end{tabular}

* U.S. score difference from OECD is statistically significant at the 0.05 level.

1. The 2003 science proficiency levels are unavailable because they were not classified as such in that year.

2. More recent reading data is unavailable because the U.S. reading test scores on the 2006 exam were invalidated by printing errors.

Sources: Lemke et al. 2004; OECD 2007; Baldi et al. 2007; OECD.

on all but one measure of achievement (see Table 1). The PISA evaluates proficiency on a scale of six levels of increasing analytical skills. Level 3 identifies students that are successful at analysis and problem-solving, while Level 2 indicates mastery of more basic descriptive tasks. While the OECD average proficiency level for mathematics, science, and reading ranked solidly in Level 3, the U.S. average for math fell from a low Level 3 in 2003 to Level 2 in 2006. In addition, the United States had greater proportions of students in the lower proficiency levels and smaller proportions of students in the medium proficiency levels than the average for mathematics and science in 2006. Given this country's socioeconomic status, researchers agree that students in the United States should be performing at a much higher level (Baldi et al. 2007; OECD 2007). In general, the reported scores on international standardized tests imply that students from the United States are not as intellectually competitive as those in other developed countries.

Of the nations that scored in the top 10 for both science and mathematics for the 2006 PISA, all but one-Canada-have unified national educational standards (Ministry of Education, Culture, Sports, Science, 
Table 2:

Public Opinion and U.S. Public Education

\begin{tabular}{|l|c|}
\hline \multicolumn{1}{|c|}{ Statement } & $\begin{array}{c}\text { Percentage of } \\
\text { U.S. adults who agree }\end{array}$ \\
\hline $\begin{array}{l}\text { U.S. schools do not adequately prepare } \\
\text { students for competition in the global job } \\
\text { market }\end{array}$ & $71 \%$ \\
\hline $\begin{array}{l}\text { If no change is made to the education } \\
\text { system, insufficient education will negatively } \\
\text { affect the economy within five to ten years. }\end{array}$ & $64 \%$ \\
\hline $\begin{array}{l}\text { If no change is made to the education } \\
\text { system, insufficient education will negatively } \\
\text { affect the economy within 25 years. }\end{array}$ & $73 \%$ \\
\hline
\end{tabular}

Note: Standard error $= \pm 2.8 \%$.

Source: Peter D. Hart Research Associates, Inc. and The Winston Group 2007.

and Technology-Japan; Finnish National Board of Education; Ministry of Education, Culture, and Sciences 2008a; Ministry of Education, Culture, and Sciences 2008b; King 2004; Alberta Government 1995-2009; Government of Canada 2009). ${ }^{5}$ Of the nine nations scoring in the bottom 10 on both science and math tests, six have nationalized systems (Montenegro, Indonesia, Colombia, Brazil, Tunisia, and Qatar), two have decentralized systems (Mexico and Argentina), and one has a hybrid system (Kyrgyzstan) (Grindle 2001; B92 News 2008; Bouwman 2009; EdInvest 2004; World Education Services 2004; ISEP 2008; Clark 2006; Supreme Education Council Qatar 2009; OSI 2002). While the success of countries with national standards does not indicate causality, it makes a national standards policy worth exploring.

These studies show a competitive disadvantage in math and science, critical subjects to technical jobs. The labor market in the United States is becoming increasingly technical, with information sectors accounting for 63 percent of GNP as far back as 1997 (Apte, Karmarkar, and Kath 2008). ${ }^{6}$ Public opinion reflects a national sense of insecurity regarding this 
lack of international competitiveness (see Table 2).

Americans today place more emphasis on the role of the federal government's role than individuals did during the founding of the nation - a time when citizens identified more strongly with their home state than with the country (Rubin 2007). U.S. citizens are highly mobile, moving about 11.7 times over the course of their lifetimes (U.S. Census Bureau 2008). Different education standards across states result in high school graduates with different levels of academic preparation, confounding employers' abilities to rely on basic skills.

States vary greatly in graduation standards, requiring as many as 24 and as few as 13 units of high school study as a prerequisite for a diploma. Some states require algebra, geometry, and algebra II coursework in mathematics, while other states do not require study beyond basic algebra. States also vary widely in their foreign language and science requirements (ECS 2008). ${ }^{7}$ Table 3 gives examples of the disparate requirements for high school graduation. To better meet both internal and external labor market demands in the United States, the quality of student preparation should meet a uniform, rigorous baseline.

The U.S. economy is moving toward information-sector jobs that require a strong technical education. However, U.S. students perform at lower levels in math and science than do students in other countries. Presently, the quality of educational content differs among the states. Public opinion and international competitiveness indicate that public $\mathrm{K}-12$ education standards and international competitiveness deserve attention.

\section{Uniform National Standards and Assessment}

This paper considers national-level standards and assessments to replace the disparate state systems. Although such a policy is not currently under political consideration, favorable views by stakeholders, including unions (Weingarten 2009; NEA 2009), business leaders (Gerstner 2008), the National Governors Association (NEA 2009), the White House (Wilson 2009), and the U.S. Department of Education (Hoff 2009) have recently increased the attention to education. For the purpose of this paper, a na- 
Table 3:

Subject Units Required for High School Graduation:

Examples of Variation Across States

\begin{tabular}{|c|c|c|c|c|}
\hline & Florida & Virginia & California & Tennessee \\
\hline English & 4 & 4 & 3 & 4 \\
\hline Math & 3 & 3 & 2 & 3 \\
\hline $\begin{array}{l}\text { Social Studies/ } \\
\text { History }\end{array}$ & 3 & 3 & 3 & 3 \\
\hline Science & 3 (2 labs) & 3 labs & 2 & 3 labs \\
\hline Health & 1 & 2 & 2 & 1 \\
\hline Arts & 1 & 1 & \multirow{2}{*}{$\begin{array}{l}1 \text { Arts or } \\
\text { Foreign } \\
\text { Language }\end{array}$} & 0 \\
\hline $\begin{array}{l}\text { Foreign } \\
\text { Language }\end{array}$ & none & none & & 0 \\
\hline Electives & 8.5 & 6 & 0 & 2 \\
\hline Other & 0.5 & 0 & 0 & 4 \\
\hline Total & 24 & 22 & 13 & 20 \\
\hline NAEP Math ${ }^{1}$ & $+4,-8$ & $+4,+8$ & $-4,-8$ & $-4,-8$ \\
\hline NAEP Writing & +8 & +8 & -8 & average \\
\hline
\end{tabular}

1. Data reported as above or below average on the 2007 NAEP. Fourth-and eighth-grade data available for mathematics; eighth-grade data only available for writing. If results were the same for both fourth- and eighth-graders in a given states, only "above" or "below" was reported.

Note: A plus sign (+) indicates above average performance at that grade level (e.g., "+4" means above average scores for fourth graders), while a minus sign (-) indicates below average performance for that grade level. One unit is one year of study.

Source: ECS 2008; U.S. Dept. of Ed 2007.

tional standards policy would replace both the current assessments given in third through eighth grades and in some high school subjects (NCLB 2001) and the current NAEP, which is given every two years to a sample of students in select grades (Vinovskis 1998). Such a change could incentivize state participation by linking participation to federal funding without 
forcibly imposing the use of a national-level system. In this way, federal education funding would encourage states and districts to implement national standards. This would mirror the process of awarding NCLB funding based on state compliance with federal requirements without creating a constitutional issue. As of 2005, federal funding contributes just 8.3 percent of total financial support for K-12 education (U.S. Dept. of Ed 2005). My proposed national standards policy would require a uniform assessment but leave funding and curricular decisions up to the states and districts.

Debate regarding the use of test data is likely to occur. Challenging situations have arisen around testing disabled students (Thurlow et al. 2005) and English language learners (Conger forthcoming). This paper does not address these specific issues.

A national standards policy would require that measurement of student academic achievement be based on a single national assessment. Specifically, the national standards and assessments should focus on English reading and writing, mathematics, and science. Given regional variation in community experience, history and social studies may need to remain under the purview of local governments. Most state and local governments teach about the state's history, which provides relevant context for students in the state.

Use of a single assessment to evaluate students in all states is not a new idea. Discussion of uniform national assessment began in the 1960s when Francis Keppel, then the U.S. Commissioner of Education, incited controversy by attempting to advance a uniform student assessment. A compromise between Keppel and the state leaders opposed to national assessment created the NAEP, but allowed data aggregation only at the regional level. This agreement prohibited state- or district-level comparisons. Policymakers struggled to apply results from the regionally aggregated data because the data lacked specificity. Beginning in 1990, states chould choose to participate in a program that would compare results at the state level. Many states did participate (Vinovskis 1998), and the program is still in place. Despite repeated discussion of expanding the use of the NAEP, states were not required to participate until the enactment of NCLB in 2002. Although George W. Bush's campaign included a policy that would have 
used the NAEP as the single measure of relative educational progress, the use of NAEP ultimately was not tied to federal funds (Rudalevige 2003). It assesses only a fraction of students at each biennial test session (U.S. Dept. of Ed. 2008b). By contrast, national standards and assessments would adhere more closely to NCLB's state-level requirements and include annual individual testing for all students in intermediate and middle grades and reasonable and appropriate high school testing. Instead of state-prepared exams, all students would have to take a national test.

\section{Analysis}

\section{Effectiveness}

An effective policy will ensure that students across the United States learn a rigorous level of content such that their post-graduation workforce contribution can increase the country's international academic competitiveness.

Given that the United States persistently lags behind its peers in education, the existing system of state-level educational standards has not produced successful competition for high school graduates in the international arena. National standards and uniform assessments would highlight regional differences in mathematics, science, and reading. High-performing schools could aid best-practice research on education policies, in much the same way that best practices improve business management. For example, evaluators could identify particularly useful instructional or organizational trends in successful schools and school systems. Researchers could then recommend ways for other educators to replicate the most effective methods. Uniform assessments would produce robust data and allow for state and district comparisons and competition that would stimulate higher achievement, thus resulting in a better-prepared workforce.

The status quo allows for some comparison across states using the NAEP. However, NAEP testing does not include all students in all schools. As such, districts have little incentive to adopt the content standards on which the NAEP is based. The NAEP does not provide standards for every grade level, because it affects only fourth, eighth, and some 
twelfth grade students. A uniform set of standards and assessments in all NCLB-tested grade levels would overcome these challenges and provide a more accurate snapshot of student knowledge. Assuming high-level standards and effective use of data to adjust instruction, this should produce graduates better prepared for the demands of the workforce.

The existing focus on state-level testing permits wide variation in the definition of "proficiency." Randi Weingarten (2009) offers a useful analogy: football fans would hardly tolerate a world in which different football teams had different definitions for a first down, allowing some to meet the goal after seven yards, while requiring 10 or even 12 yards of other teams. The status quo allows some students to "pass" without meeting sufficiently rigorous standards, resulting in the weakness of intellectual competition from American students.

The critical issue facing a national policy is standard-setting. Essentially, the question is whether the national-level standards landed at the proverbial seven-yard requirement or at the 10- or 12-yard mark. National standards and assessments would only be useful if they increased the overall level of content instruction by adopting standards consistent with the highest performing states.

Although it is difficult to precisely predict the effectiveness of national standards and assessments, the policy of uniform national standards and assessments would have several secondary effects that would improve the overall functionality of the educational system. At present, a teacher wishing to move from one state to another must adapt to significantly different content-area standards. If teachers did not have to learn an idiosyncratic set of state standards in order to transfer from one region to another, they would be able to relocate and meet educational labor market demands more easily. This process could reduce reliance on less-qualified teachers in areas with chronic demand.

Uniformity of standards might also create a better market for research and development of educational tools because researchers developing these tools could market them to school systems across the country, not just in specific states. Improved curricular tools would provide better learning opportunities for students, reinforcing challenging concepts and yielding a 
higher-quality workforce. National standards and assessments would also allow states and localities to focus on areas of educational administration apart from developing, approving, and updating standards (Miller 2008). The emphasis on instruction, administration, and operations over standards development would focus local school administrators' resources on student outcomes. This could improve student achievement and, by extension, international competitiveness.

A potential unintended consequence of national $\mathrm{K}-12$ standards and assessment may be increased drop-out rates. If students felt labeled or demoralized by poor scores, or became bored by repetitive testing, the students might choose to leave school, thereby reducing the overall level of preparedness in the workforce. New York faces unusually low graduation rates due to requirements mandating that students pass rigorous state exams (NYC Coalition for Educational Justice 2009). Uniform standards and national assessments, however, do not include graduation requirements-only testing requirements. It is hard to say whether NCLB causes or even correlates with decreased high school graduation rates because states have widely varying ways of calculating graduation rates. Although the Department of Education recently issued non-regulatory guidance on reporting graduation rates uniformly (U.S. Dept. of Ed. 2008), disparate methods and incomplete data still plague the field, which confounds conclusions (IES 2006). Comparative graduation rates would be more valid in the future if states comply with uniform graduation reporting. However, uniform data is not available for the period before NCLB. The risk of increased drop-out rates is difficult to quantify in a data-poor environment and the link between high-stakes tests and drop-out rates (and international competition, because students lacking at least a high school background would be even less competitive than under the status quo) is challenging to evaluate.

National standards and assessments are more likely than the status quo to be effective at improving overall student learning and workforce competitiveness. This option depends on the rigor of the national standards and the consequences of not meeting expected measures. Assuming that the national standards and assessments raise expectations to the level of the highest state standards, U.S. students should become more internationally 
competitive. The existing practice of state-level standards and assessments provides no means of raising expectations. In fact, NCLB requirements create perverse incentives to dilute state-level expectations because the law demands that all students eventually meet proficiency. One way for states to accomplish this is to make the standards and assessments easier so that state-level passage rates become inflated. Provided that national standards are high and schools rise to the challenge in raising student achievement, it is likely that a policy of national standards and assessments is the more effective option for enhancing international competitiveness of graduates.

\section{Political Feasibility}

Given that education affects multiple layers of government, a politically feasible solution would need to garner majority support from Congress, the White House, and a majority of states within four years. Accurate predictions of future political coalitions are challenging, and the significant change required by the adoption of a policy of national standards and assessments cannot happen overnight. Thus, the time frame of one presidential term makes sense, since it offers time for negotiation while isolating a given political atmosphere. Notably, given that other major federal education changes, such as the passage of the 1965 Elementary and Secondary Schools Act and the NCLB each closely followed an inauguration. Political feasibility does not rest solely with any one group, but relies on consensus-building.

The intensity of past controversy over national standards (Vinovskis 1998) provides some evidence that passage is not guaranteed. However, the current economic climate may have a two-pronged effect on attitudes toward national standards and testing. Americans are increasingly concerned with workplace competition (Jacobe 2009) and are more willing to allow increased federal control in many other areas of life, specifically corporate functions (Appelbaum 2009).

A consensus has been forming in the education policy community. High-profile endorsements of uniform national standards have come from the president of the American Federation of Teachers (AFT, a national teachers' union), Randi Weingarten, the National Education Association (NEA, another major teachers' union), President Obama, the National 
Governors Association (NGA), and Louis Gerstner, former CEO of IBM (Weingarten 2009; Wilson 2009; NEA 2009; Gerstner 2008). The impact of Randi Weingarten's public support cannot be overstated. It implies the support of millions of teachers, many of whom were highly vocal critics of state-level assessments with NCLB (Rudalevige 2003). The NEA recently released a statement indicating that it joined the Common Core State Standards Initiative, a voluntary plan to establish unified English $\&$ language arts, math, and science standards. This support highlights a change in attitudes toward national standards and testing. Teachers' unions are a critical Democratic constituency, and thus influential in an environment governed by a Democratic president and Democratic leadership in both houses of Congress. The Common Core State Standards Initiative also boasts the support of the NGA and the National Association of State Boards of Education (NEA 2009). Gerstner (2008) points out that most Americans favor national standards. A 2007 ETS study supports his conclusion, showing that 64 percent of those asked would support federal standard-setting for education (Peter D. Hart Research Associates, Inc. and The Winston Group 2007, 10). President Obama recently voiced his support for national-level academic standards while emphasizing a range of reform techniques (Wilson 2009). Thus, although history would suggest political challenges, recent developments highlight changing stakeholder and political sentiment. Because politicians are accountable to their constituents, the increasing support will most likely make federal standards politically feasible.

A serious counterargument to national standards and evaluation concerns the constitutional role of the federal government in education. Mandating cooperation with specific standards and assessments would require a significant advance of federal authority in $\mathrm{K}-12$ education, potentially requiring changes to the Constitution. However, because the proposed standards and assessments for education would be voluntary, by linking federal aid with compliance, Congress could enact this form of national standards and assessments without raising the issue of constitutionality. Notably, no states refuse NCLB funds (New America Foundation), in spite of the significant increase of federal regulation it imposes. Because 
national standards and assessments could be enacted in the same way as NCLB requirements, these standards and assessments are politically feasible with respect to the states and the Constitution.

Given that Congress failed to agree on a new version of NCLB in 2008 , coming to a consensus could be challenging. However, the gridlock of 2008 has shifted in the current political circumstances with a changeoriented Democratic president and Democratic majorities in both houses of Congress. Thus, the impasse of last year may be a poor predictor of current feasibility.

While political action can be challenging, a significant consensus is building among stakeholders. With states, teachers' unions, federal officials, the President, and the business community all interested in national standards and assessments, political feasibility of national standards and assessments seems strong. As long as participation is voluntary and incentive-based (as opposed to legally mandated), passage is likely. Overcoming the inertia of the status quo is almost always a political challenge, merely because the status quo enjoys natural political feasibility. Uniform standards and assessments and the status quo are both politically viable.

\section{Cost}

Education is the single largest government expenditure at the local level and a significant overall taxpayer commitment (Lee, Johnson, and Joyce 2008). In 2004 and 2005, total elementary and secondary education spending exceeded $\$ 530$ billion (U.S. Dept. of Ed. 2005). The national standards and assessment policy will be evaluated by whether and to what extent it reduces cost compared to the status quo.

States currently spend extensive resources creating, manufacturing, administering, and scoring standardized tests. A 1993 Governmental Accountability Office (GAO) report estimated that the costs of preparing and administering tests at the state and local level were about 50 percent higher than the costs of the same assessment at a national level. Ten years later, the GAO issued a report estimating that states would spend between $\$ 1.9$ and $\$ 5.3$ billion on $\mathrm{K}-12$ student assessments during the FY 2002 through FY 2008, depending on the mix of assessments given (GAO 2003). This 
report encouraged the Department of Education to facilitate state cooperation on test preparation in an effort to reduce costs and indicated that some of the expenses to multiple assessments are unnecessarily repetitive. At a minimum, centralizing the process by using a single national test should not be more expensive, and estimates suggest that producing national assessments would be significantly less expensive than continuing to develop tests at the state level. Because NCLB specifies that state assessments be standards-driven, traditional aptitude tests like the Stanford 9 no longer provide state-level assessment data. States must generate their own assessment tools aligned to their own standards, which yields over 50 tests.

Creating national standards would require some initial investment. Experts might draw on existing standards in certain states, which would minimize expenses. The cost of setting national standards would not likely outweigh the potential savings from producing a single test. If national standards elevate the educational experience of students, graduates would create a better-prepared workforce and ensure that future workers in the United States could compete for information-based jobs.

National standards and assessments would also streamline production of student and teacher preparation materials. Whereas there are currently more than 50 sets of guidelines on ways to implement standards, one definitive set of support materials could be produced to prepare students and teachers for national standards. Additionally, education colleges in various states currently use different materials to prepare teachers for the statelevel standards. The creation of national standards would eliminate extra costs associated with preparing separate information at each state education agency.

National standards and assessments would reduce costs. Creating, producing, and scoring one test is more cost-effective than the status quo of administering different tests by state education agency.

\section{Administrative Feasibility}

A policy with strong administrative feasibility can be implemented quickly and easily, and requires the creation of very few new bureaucratic structures. Such a policy either requires little on-the-ground work or utilizes 
existing systems to achieve functionality with few demands on either government or citizens.

An existing entity, the National Assessment Governing Board (NAGB), oversees the creation and administration of the NAEP. The NAGB is a representative body that includes various education stakeholders. This group has the ability to take the lead in expanding the national test. Existing hierarchies of state and local education agencies already cooperate to ensure implementation of state tests. These existing structures could likely administer the national assessments if testing students on the national test were necessary for states and districts to receive federal funding. In addition, current national tests, such as the SAT or ACT, enjoy effective implementation. There is no reason to assume that a national assessment would be challenging to administer. Thus, nationalized standards and assessments are administratively feasible. Additionally, the national preparation of scores and results should reduce the administrative burden on states. The use of existing structures decreases state-level burdens and allows strong administrative feasibility of national standards and assessments.

Even though NCLB created a significant administrative burden at the outset, many issues have been worked out through the Department of Education's rulemaking and state and local administration. Now in 2009, eight years after the passage of NCLB, structures are in place for state and local administration. Thus, the status quo is highly administratively feasible.

Changing policy from state-level to national-level standards and assessment would have some initial effects but should not increase-and would likely reduce-the overall administrative burden. The status quo will always require less administrative flexibility than does a new policy. However, existing compliance with NCLB reduces the challenges of implementing national standards and assessment because educators currently use standards-based assessments. Substituting the use of one assessment instrument for another should present a minimal burden. The status quo and national standards and assessments fare nearly evenly in administrative feasibility. 


\section{Conclusion}

Shifting standards and assessments from state to federal administration will likely be more effective in increasing student achievement and less costly than the status quo. As long as national standards set the threshold for student achievement at a high level, the system will prepare students in the United States for the technical challenges of the workforce. National standards and assessments are politically feasible if couched in the same manner of NCLB, which uses federal funding incentives instead of regulatory mandates. A significant coalition has been building in favor of national standards, making their passage more likely than in the past, but by no means assured. National standards and assessments would impose a minimal burden and would ease state-level duties in scoring and reporting. National standards and assessments offer important benefits and long term improvements.

Public decisionmaking on education is not simple. Clear trade-offs exist between state-level authority and national cohesion. Since the implementation of No Child Left Behind in 2002, variations among school performances have become easier to understand. National standards and assessments would further clarify areas of strength and weakness. Jurisdictions are naturally competitive (Brunori 2003) and would have incentives to improve as a way to attract residents and ensure local workforce adequacy. Future education policy could further incentivize improvement for lagging districts. While standardized testing is imperfect, it provides a beginning for candid dialogue and national self-reflection, which could lead to targeted support and improvement. The market for global intellectual capital is tight, and national standards and assessments would improve the competitiveness of the labor force in the United States.

\section{References}

Alberta Government. 1995-2009. Alberta education.

http://www.education.alberta.ca/ (accessed February 26, 2009). Appelbaum, Binyamin. 2009. Expanded rescue of banks outlined: U.S. to help if firms can't find capital. Washington Post, 26 February, D01. 
Apte, Upte M., Uday S. Karmarkar, and Hiranya N. Kath. 2008. Information services in the U.S. economy: Value, jobs, and implications. California Management Review 50(3): 12-65.

B92 News. 2008. All textbooks in Montenegrin from 2009. B92, 30

December, Region. http://www.b92.net/eng/news/

region-article.php?yyyy $=2008 \& \mathrm{~mm}=12 \& \mathrm{dd}=30 \&$ nav_id $=56091$ (accessed March 27, 2009).

Baldi, Stephane, Ying Jin, Melanie Skemer, Deborah Herget, and Holly Xie. 2007. Highlights from PISA 2006: Performance of U.S.

15-year-olds in science and mathematics literacy in an international context. Washington, DC: National Center for Education Statistics. http://nces.ed.gov/pubs2008/2008016.pdf (accessed November 2007).

Bouwman, Astrid. 2009. Be prepared to make the jump. Jakarta Post, 24 March, Lifestyle. http://www.thejakartapost.com/ news/2009/03/24/be-prepared-make-jump.html (accessed March 28, 2009).

Brunori, David. 2003. Local tax policy. Washington, DC: The Urban Institute Press.

Clark, Nick. 2006. Education in Tunisia. World education news and review. April, Practical Information. http://www.wes.org/ewenr/06apr/ practical_tunisia.htm (accessed March 28, 2009).

Conger, Dylan. Forthcoming. Testing, time limits, and English learners: Does age of entry affect how quickly students can learn English? Social Science Research.

EdInvest News. 2004. The education system in Argentina. World Bank Group. http://fr.excelafrica.com/showthread.php?t=2850 (accessed March 28, 2009).

Education Commission of the States (ECS). 2008. Standard high school graduation requirements (50-state). http://mb2.ecs.org/reports/Report.aspx?id=735 (accessed March 28, 2009).

Finnish National Board of Education. Education structure/

Basic education. http://www.oph.fi/english/ page.asp?path $=447,4699,88622,4847$ (accessed February 26, 2009). 
Gerstner, Louis V. 2008. Lessons from 40 years of education 'reform.' Wall Street Journal, 1 December, Opinion.

Government Accountability Office (GAO). 1993. Student testing: Current extent and expenditures, with cost estimates for a national examination. Washington, DC: General Accounting Office.

- 2003. Title I: Characteristics of tests will influence expenses; Information sharing may help states realize efficiencies. Washington, DC: Government Accountability Office.

Government of Canada. 2009. Departments and Agencies. 13 February. http://canada.gc.ca/depts/major/depind-eng.html (accessed February 26, 2009).

Grindle, Merilee S. 2001. Education reform in Mexico. Revista: Harvard review of Latin America. http://www.drclas.harvard.edu/revista/ articles/view/74 (accessed March 27, 2009).

Hoff, David J. 2009. National standards gain steam. Education Week, 4 March.

Institute of Education Sciences (IES). 2006. Computing high school graduation rates. Washington, DC: U.S. Department of Education.

International Student Exchange Programs. 2008. Country handbooks: Brazil education. http://www.isep.org/Students/Placed/ handbook_education.asp?country=7 (accessed March 28, 2009). Jacobe, Dennis. 2009. Job-market pessimism reaches new high. Gallup. 20 February. http://www.gallup.com/poll/115324/ Job-Market-Pessimism-Reaches-New-High.aspx (accessed February 26, 2009).

King. August 31, 2004. Basic education in china. http://english.china.com/zh_cn/education/ educational_system/11020788/20040831/11856713.html (accessed February 26, 2009).

Kober, Nancy, Naomi Chudowsky, and Victor Chudowsky. 2008. Has student achievement increased since 2002? State test score trends through 2006-07. Washington, DC: Center on Education Policy.

Lee, Robert D., Ronald W. Johnson, and Philip G. Joyce. 2008. Public Budgeting Systems., 8th Edition Boston, MA: Jones and Bartlett 
Publishers.

Lemke, M. et al. 2004. International outcomes of learning in mathematics literacy and problem solving: PISA 2003 results from the U.S. perspective. Washington, D.C.: National Center for Education Statistics.

McCaffrey, Daniel F., Laura S. Hamilton, Brian M. Stecher, Stephen P. Klein, Delia Bugliari and Abby Robyn. 2001. Interactions among instructional practices, curriculum, and student achievement: The case of standards-based high school mathematics. Journal for Research in Mathematics Education 32(5): 493-517.

Miller, Matt. 2008. Nationalize the schools (... a little)! Washington, DC: Center for American Progress.

Ministry of Education, Culture, and Sciences. 2008a. Primary Education. 6 April. http://www.minocw.nl/english/education/292/ Primaryeducation.html (accessed April 15, 2009).

_.2008b. Secondary Education. 6 April. http://www.minocw.nl/ english/education/293/Secondaryeducation.html (accessed February 2009).

Ministry of Education, Culture, Sports, Science, and Technology-Japan. Improvement of Academic Ability. http://www.mext.go.jp/english/org/ struct/014.htm (accessed February 25, 2009).

National Education Association (NEA). 2009. NEA partners to develop standards for measuring 21st century skills. National Education Association 2009 News releases, 23 February. http://www.nea.org/home/ 30696.htm (accessed March 8, 2009).

New America Foundation. Federal Education Budget Project. http://www.newamerica.net/education_budget_project/ (accessed March 9, 2009).

No Child Left Behind Act of 2001. U.S. Public Law 107-110. 107th Congress, January 8, 2002. http://www.ed.gov/policy/elsec/leg/ esea02/107-110.pdf (accessed April 15, 2009).

NYC Coalition for Educational Justice. 2009. Looming crisis or historic opportunity? Meeting the challenge of the regents graduation standards. New York City: NYC Coalition for Educational Justice.

Open Society Institute-Education Support Program (OSI). 2002. 
Education development in Kyrgyzstan, Tajikistan and Uzbekistan: Challenges and ways forward. http://www.soros.org/initiatives/esp/ articles_publications/publications/development_20020401/ education_development.pdf (accessed March 28, 2009).

Organization for Economic Cooperation and Development (OECD). 2007. PISA 2006: Science competencies for tomorrow's world volume 1: Analysis. Paris: OECD.

—. OECD Programme for International Student Assessment. http://www.pisa.oecd.org (accessed April 9, 2009).

Patton, Carl V., and David S. Sawicki. 1993. Basic Methods of Policy Analysis and Planning. Upper Saddle River, NJ: Prentice Hall.

Peter D. Hart Research Associates, Inc. and The Winston Group. 2007. Standards, accountability, and flexibility: Americans speak on No Child Left Behind reauthorization. Princeton, NJ: Educational Testing Services.

Rubin, Edward L. 2007. Puppy federalism and the blessings of America. In American Intergovernmental Relations: Foundations, Perspectives, and Issues, XX Laurence J. O'Toole. Washington, DC: CQ Press, $100-111$.

Rudalevige, Andrew. 2003. The Politics of No Child Left Behind. Educaton Next 3(4): 63-69.

Schoen, Harold L., Kristin J. Cebulla, Kelly F. Finn and Cos Fi. 2003. Teacher variables that relate to student achievement when using a standards-based curriculum. Journal for Research in Mathematics Education 34(3): 228-259.

Supreme Education Council Qatar. 2009. National tests to begin in April. News Articles, 12 March. http://www.english.education.gov.qa/ content/resources/detail/7352 (accessed March 28, 2009).

Thurlow, Martha L., Sheryl S. Lazarus, Sandra J. Thompson, and Amanda Blount Morse. 2005. State policies on assessment participation and accommodations for students with disabilities. Journal of Special Education 38(4): 232-240.

U.S. Census Bureau, Population Division, Journey-to-Work and Migration Statistics Branch. 2008. Geographic Mobility/Migration. 21 Oc- 
tober. http://www.census.gov/population/www/socdemo/migrate/ cal-mig-exp.html (accessed March 12, 2009).

U.S. Department of Education. 2005. 10 facts about K-12 education funding. http://www.ed.gov/about/overview/fed/10facts/10facts.pdf (accessed April, 8 2009).

2007. Mathematics and writing report cards, State comparisons. http://nationsreportcard.gov/ (accessed March 28, 2009).

-2008a. High school graduation rate non-regulatory guidance. http:// www.ed.gov/policy/elsec/guid/hsgrguidance.pdf (accessed April 8, 2009).

-2008b. NAEP Overview. http://nces.ed.gov/nationsreportcard/ about/\#naepreport (accessed February 26, 2009).

Vinovskis, Maris A. 1998. Overseeing the Nation's Report Card: The Creation and Evolution of the National Assessment Governing Board (NAGB). Washington, DC: Institute for Social Research, School of Public Policy University of Michigan.

Weingarten, Randi. 2009. The case for national standards. Washington Post, 16 February, A15.

Wilson, Scott. 2009. Obama says public schools must improve. Washington Post, 11 March, A1.

World Education Services. 2004. Colombia education overview. 6 May. http://www.wes.org/ca/wedb/colombia/coedov.htm (accessed March 28, 2009).

\section{Notes}

1. Equivalent units include "State Education Agencies" for territories not recognized as states, such as the District of Columbia, the Department of Defense Education Activity, and Puerto Rico. These entities create standards and assessments for students in their jurisdictions separately from the 50 states.

2. The law sets the goal that all students will be proficient by 2012 .

3. In 2003 only, PISA also assessed a multidisciplinary "problem solving" category (OECD). Results are not considered here because this occurred in only one year; mathematics, science, and reading tests have been ongoing. 
4. More recent reading data is unavailable because the U.S. reading test scores on the 2006 exam were invalid due to printing errors. Note also that the total number of countries, 41 , includes some partner nations that are not yet OECD members.

5. Canada has provincial, not national, standards (Government of Canada 2009).

6. Apte, Karmarkar, and Kath define the "information" sectors as those requiring the use of computing and/or data skills.

7. High school graduation requirements are an imperfect indicator of quality and of content standards. However, they do provide summary comparisons where qualitative comparisons of content standards prove unwieldy.

Jessica McKinney is a Master of Public Policy candidate in the Trachtenberg School, where she has concentrated on budgeting/public finance. A 2004 graduate of Georgetown University, Jessica taught elementary school prior to entering the M.P.P. program. During graduate school, she has maintained her connection with students by coordinating the Anacostia Public Service Academy Tutoring Program and working at the central office of D.C. Public Schools. Jessica's policy area of interest is elementary and secondary education, and she is particularly passionate about urban education reform.

The author would like to thank Sarah Hassaine, Lauren Bloom, Lisa Pettibone, and Micah Elggren for their heroic dedication this article. She would also like to thank Professors Dylan Conger and Stephanie Cellini for their insightful comments; colleagues Matt Van Itallie and Monica Swinney for the challenging debates that inspired this work; and her parents, Richard and Dorothy McKinney, for their support. 